\title{
Knowledge acquired, satisfaction attained and attitudes towards shared decision making in colorectal cancer screening
}

\author{
Francisco J. Garcia-Alonso, María Hernández Tejero, Daniel Bonillo Cambrodón, Fernando Bermejo \\ Fuenlabrada University Hospital, Fuenlabrada, Spain
}

Abstract

Background Introducing shared decision making (SDM) in colorectal cancer (CRC) screening requires patients to acquire appropriate knowledge. We aimed to describe the knowledge attained by subjects with a family history of CRC.

Methods Consecutive patients attending the gastroenterology clinic for a CRC family history were invited to take part in a cross-sectional survey. Attitudes towards SDM, satisfaction with the information received, knowledge currently achieved, and relevant influencing factors were evaluated. Satisfaction and attitudes towards SDM were evaluated with Likert scale questions. Knowledge was surveyed with closed (80\%) and open (20\%) questions.

Results Of the 160 patients, $42.7 \%$ were male and the median age was 51.8 years (interquartile range: 43.9-58.5). Most subjects favored SDM; only 12.8\% (8.4-19.1\%) favored passive attitudes. Satisfaction with the information received about what a colonoscopy is and why it is recommended was adequate in $83.1 \%$ (76.4-88.2\%). Information about risks satisfied $62.9 \%(55-70.1 \%)$ and about alternatives to colonoscopy only $30.6 \%$ (23.8-38.3\%). The benefits of screening were better known than its risks and alternatives. The CRC decrease associated with screening was known to $71.3 \%$ (63.7-77.8\%), but only 38.5\% (31.1-46.4\%) knew that a reduced risk still exists. Just $21.2 \%$ (15.5$26.9 \%$ ) could mention an alternative screening method to colonoscopy and only $42.5 \%$ (35-50.4\%) were aware of any associated harm. On multivariate analysis, higher educational level and younger age of the attending physician were associated with higher knowledge scores.

Conclusion SDM is considered favorably by most patients. Although information about the benefits of CRC screening is transmitted adequately, risks and alternatives should be better addressed.

Keywords Colorectal cancer, shared decision making, cancer screening, educational status, health knowledge, attitudes, practice

Ann Gastroenterol 2017; 30 (1): 1-7

\section{Introduction}

Colorectal cancer (CRC) is the third most common cancer diagnosed worldwide in men and women and the second cause of cancer-related death [1]. CRC screening increases the proportion of patients diagnosed at early stages $[2,3]$ and

Gastroenterology Department, Fuenlabrada University Hospital, Fuenlabrada, Spain

Conflict of Interest: None

Correspondence to: Francisco Javier Garcia-Alonso, MD, Camino del Molino 2, Fuenlabrada, 28942 Madrid, Spain, Tel.: +34 916006303,

Fax: +34 916006100, e-mail: fj.garcia.alonso@gmail.com

Received 6 July 2016; accepted 23 August 2016

published online 30 September 2016

DOI: http://dx.doi.org/10.20524/aog.2016.0090 decreases the incidence of CRC in the following years. This reduction varies among published studies [4-6]. On the other hand, no study to date has demonstrated a decrease in all-cause mortality.

Colonoscopy and immunochemical fecal occult blood testing are the most frequently recommended screening methods for patients with average risk. Subjects with affected relatives (excluding inherited CRC syndromes) present a 2- to 3-fold higher risk than average, depending on the number of affected family members [7]. Although there are no randomized trials comparing different options in these subjects, colonoscopy is the recommended screening method [8]. Cancer screening also entails potential harm, which is often inadequately reported in the literature [9]. More importantly, colonoscopy differs from other cancer screening methods in its invasive nature and the need for preparation before the test [10].

Patients' participation in decision-making processes is increasing [11]. Proper information is key to reaching 
decisions, but patients included in screening programs often show a significant lack of knowledge about the procedure, its aims, risks and benefits [12]. In this study, we aimed to describe our participants' knowledge and their satisfaction with the information given, their attitude towards shared decision making (SDM) and the factors influencing them.

\section{Patients and methods}

This cross-sectional survey was approved by the research committee as part of the Quality Control Program of our unit, which serves an area of 260,000 inhabitants in Spain and performed 2730 colonoscopies in 2014.

\section{Patient selection}

All consecutive patients who attended the outpatient clinic for CRC family history and were invited to participate in the CRC screening program between April $16^{\text {th }}$ and August $31^{\text {st }} 2014$ were evaluated. Patients were attended by 12 different physicians with a median age of 40.5 (interquartile range: 31.25-52.75). Patients diagnosed with inherited CRC syndromes or those who could not understand the questionnaire (language skills, hearing impairment, etc.) were excluded. The questionnaire was conducted over the telephone by experienced interviewers. At least 5 calls were made at different times before the patient was classed as unreachable. The time needed to answer ranged between 30 and $60 \mathrm{~min}$.

\section{Survey description}

The questionnaire was composed of 35 questions divided into four domains: demographic data, confounding factors, satisfaction, and knowledge questions. Possible confounding factors were: educational level, family members affected, age and year of diagnosis, attending gastroenterologist, time elapsed between visit and interview, sources of information, previous screening procedures, and preferred involvement in decision making. This last item was assessed with a question based on the Control Preference Scale, as described elsewhere [13]. Sources of information were assessed by a multiple choice question offering different possibilities. Up to 3 choices per patient were allowed.

\section{Knowledge and satisfaction survey development}

First, we identified which pieces of information are important to the patient. To do so, we considered the following 4 questions:

- What is the problem?

- What are my options?
- What are the possible benefits and how likely are they?

- What are the possible harms and how likely are they?

These questions were modified from the study published by Shepherd et al [14], where the last 3 significantly improved the information given by family physicians. We developed the survey by addressing the information required to answer these questions. Statements answered in a "true/false/don't know" manner were as follows:

- Subjects with family members who have CRC present a higher risk of developing this illness compared with patients who have no family history (true).

- CRC diagnosed during screening procedures is usually less extensive and presents a better prognosis compared with CRC diagnosed in people presenting symptoms (true).

- CRC screening reduces the risk of developing CRC (true).

- CRC eliminates the risk of developing CRC for 3 years after screening (false).

- CRC screening has proven to lengthen life expectancy (false).

- A good bowel cleansing increases the number of polyps detected (true).

An open question evaluated knowledge of alternatives to colonoscopy. Risks were addressed with one open question (Do you know any possible harms related to colonoscopy?) and one multiple choice question regarding how likely they are. Possible answers to open questions were listed, including various synonyms (e.g., colonic perforation, tear, rupture, explosion, wound). Answers not included in the list were discussed on a one-by-one basis.

In order to ascertain satisfaction, patients were first asked if they were "satisfied overall" and then asked a series of directed questions about the information received using a 4-point Likert scale ("abundant/more than enough", "enough", "not enough", "poor/none") to eliminate the "people pleasing" bias. Satisfaction questions were asked before the knowledge assessment.

\section{Objectives and outcomes}

The aim of this study was to describe the knowledge attained by subjects with CRC family history in our outpatient clinic. A knowledge score was created, awarding 1 point for each correct answer and 1 extra point if they could mention 2 or more possible colonoscopy-related harms. The score ranged from 0 to 10 . Secondary objectives identified attitudes towards SDM, determining the factors that affected the level of knowledge acquired, and evaluating the relationship between patients' satisfaction and the actual knowledge acquired.

\section{Sample size, bias assessment}

An initial group of 30 patients completed the questionnaire. This group was selected according to the above criteria. It 
included those who attended between February 20 2014 and March 30th 2014 and had no previous screening interventions. We used this first survey to further correct it for better understanding and to estimate the population's overall knowledge (mean score: 4.8, standard deviation, SD: 0.92). A sample size of 96 patients was calculated as sufficient to detect a 0.2 point difference in the mean score $(\alpha=0.05$, $\beta=0.8$ ), assuming a total of 350 new patients annually whose family history of CRC was examined. As patients with previous screening rounds might have gained knowledge from them, they were excluded from the sample size calculation.

In order to minimize the observation bias, only 2 members of the department (FJGA and FB) developed the survey, keeping the physicians attending the included patients unaware of the aims and contents of the survey. Surveys were started in early September 2014. In an attempt to avoid sampling and self-selection bias, consecutive patients were enrolled and a choice of different interview times was offered.

\section{Statistical analysis}

The analysis was performed with STATA (StataCorp. 2013. Stata Statistical Software: Release 13. College Station, TX: StataCorp LP). Data were summarized as mean (SD), median (interquartile range) or proportions (95\% confidence intervals), as warranted. Chi-square tests were used to determine differences between categorical variables. Student's $t$-test was employed to compare normally distributed continuous variables and Wilcoxon rank sum test was used for those not normally distributed. Multinomial logistic regression was employed to test attitudes towards SDM, establishing 3 categories: active, collaborative, and passive subjects. Poisson and negative binomial regression models were applied to test the knowledge score; results were expressed using the incidence rate ratio (IRR), which expresses the change in the dependent variable in terms of a percentage, representing the amount by which the IRR is either above or below 1 . Potential predictors were first assessed by univariate analysis. Significant predictors $(\mathrm{P}<0.20)$ in univariate analysis were then evaluated in multiple regression models, using bidirectional elimination.

\section{Results}

A total of 205 potentially eligible patients attended the outpatient clinic between April 16 ${ }^{\text {th }} 2014$ and August $31^{\text {st }} 2014$. The patient selection process is shown in Fig. 1. All 4 patients excluded for inherited CRC syndromes presented Lynch syndrome. Patients' baseline characteristics are shown in Table 1.

\section{Satisfaction}

Overall satisfaction was first evaluated. Most patients answered favorably; $56(35.2 \% ; 28.1-43.3 \%)$ were very

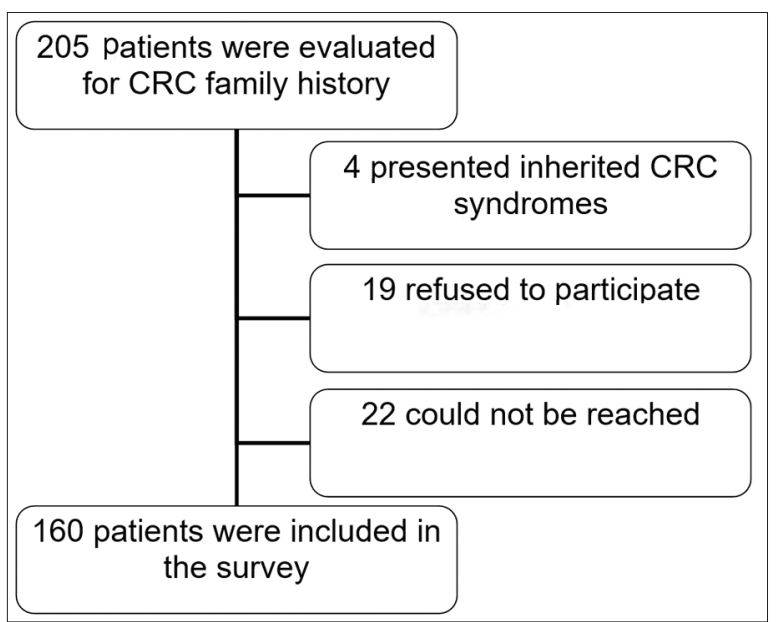

Figure 1 Flowchart of patients who attended the outpatient gastroenterology clinic for colorectal cancer (CRC) family history

satisfied and 70 (44\%; 36.4-51.9\%) were moderately satisfied. Answers to concrete questions regarding information received are shown in Fig. 2. Most patients (83.1\%; 76.4$88.2 \%$ ) considered the information received about why CRC screening was recommended and what a colonoscopy involves to be sufficient or more than sufficient. On the other hand, the proportion of patients who considered the information received about associated risks to be abundant or sufficient was lower, at $62.9 \%$ (55-70.1\%), and dropped to $30.6 \%$ (23.8-38.3\%) when subjects were asked about alternatives to colonoscopy.

\section{Source of information}

Each patient mentioned a mean of 2 (SD: 0.88) different sources. Fig. 3 shows the proportion of subjects mentioning each source. Family and friends were chosen by $57.2 \%$ (49.1-65\%) of our subjects. Less than $40 \%$ of our participants mentioned their primary care physician or the gastroenterologist. Other physicians were mentioned by $30.8 \%$ (23.7-38.6\%), referring mainly to oncologists and surgeons attending the affected relatives of our interviewees.

\section{Preference for decision control}

A total of 156 subjects exposed their preferences. Shared responsibility was chosen by $68(43.6 \% ; 35.9-55.6 \%)$. Active roles were favored by $68 ; 10(6.4 \% ; 3.5-11.6 \%)$ preferred to decide on their own, while $58(37.2 \% ; 29.9-45.1 \%)$ would make the choice after considering their doctor's recommendation. Twenty participants (12.8\%; 8.4-19.1\%) declared a preference for passive attitudes. Sixteen (10.3\%; 6.3-16.2\%) would like their doctors to choose after considering their opinions and $4(2.6 \% ; 1-6.7 \%)$ wished their doctors to decide for them. No association could be established between the evaluated variables (sex, age, educational level, number or type of 
Table 1 Baseline characteristics of subjects attended in the outpatient gastroenterology clinic

\begin{tabular}{|c|c|c|c|c|}
\hline & $\begin{array}{c}\text { Overall } \\
(\mathrm{n}=160)\end{array}$ & $\begin{array}{c}\text { First } \\
\text { screening } \\
\text { round }(n=96)\end{array}$ & $\begin{array}{c}\text { Subsequent } \\
\text { screening } \\
\text { rounds }(n=64)\end{array}$ & $\mathrm{P}$ \\
\hline Age, median (IQR) & $51.8(43.9-58.5)$ & $47(41.5-55.1)$ & $56.6(50.4-62.2)$ & $<0.001$ \\
\hline Sex, \% males (n) & $42.7(68)$ & $39.6(38)$ & $50(32)$ & 0.1 \\
\hline Number of previous screening rounds, median (IQR) & $0(0-1)$ & $0(0-0)$ & $1(1-2)$ & $<0.001$ \\
\hline $\begin{array}{l}\text { Time (days) elapsed between outpatient visit and } \\
\text { interview, median, (IQR) }\end{array}$ & $92(65-123)$ & $90(52-109)$ & $104(86-137)$ & 0.004 \\
\hline At least 1 first-degree relative diagnosed with CRC, \% (n) & $91.9(147)$ & $88.5(85)$ & $96.9(62)$ & 0.16 \\
\hline $\begin{array}{l}\text { Number of relatives diagnosed with } \\
\text { CRC, median (IQR) }\end{array}$ & $1(1-2)$ & $1(1-2)$ & $1(1-2)$ & 0.52 \\
\hline $\begin{array}{l}\text { Time elapsed between diagnosis of the most recent } \\
\text { relative and outpatient visit, median (years), (IQR) }\end{array}$ & $10.2(4.2-19.1)$ & $6.3(2.2-15.3)$ & $12.3(7.4-20.2)$ & 0.001 \\
\hline $\begin{array}{l}\text { Age at diagnosis of the youngest relative affected, } \\
\text { median (IQR) }\end{array}$ & $62(54-71)$ & $63(55-72)$ & $60(51-70)$ & 0.16 \\
\hline Have read the informed consent form, \% (n) & $65.4(104)$ & $57.4(55)$ & $77.4(49)$ & 0.01 \\
\hline Education & & & & 0.59 \\
\hline None \% (n) & $6.3(10)$ & $5.2(5)$ & $8.3(5)$ & \\
\hline Primary school \% (n) & $38.1(61)$ & $36.2(35)$ & $41.7(26)$ & \\
\hline High school \% (n) & $47.5(76)$ & $48.9(47)$ & $45(29)$ & \\
\hline Bachelor or higher\% (n) & $8.1(13)$ & $9.6(9)$ & $5(4)$ & \\
\hline
\end{tabular}

IQR, interquartile range; $n$, number of subjects; $C R C$, colorectal cancer

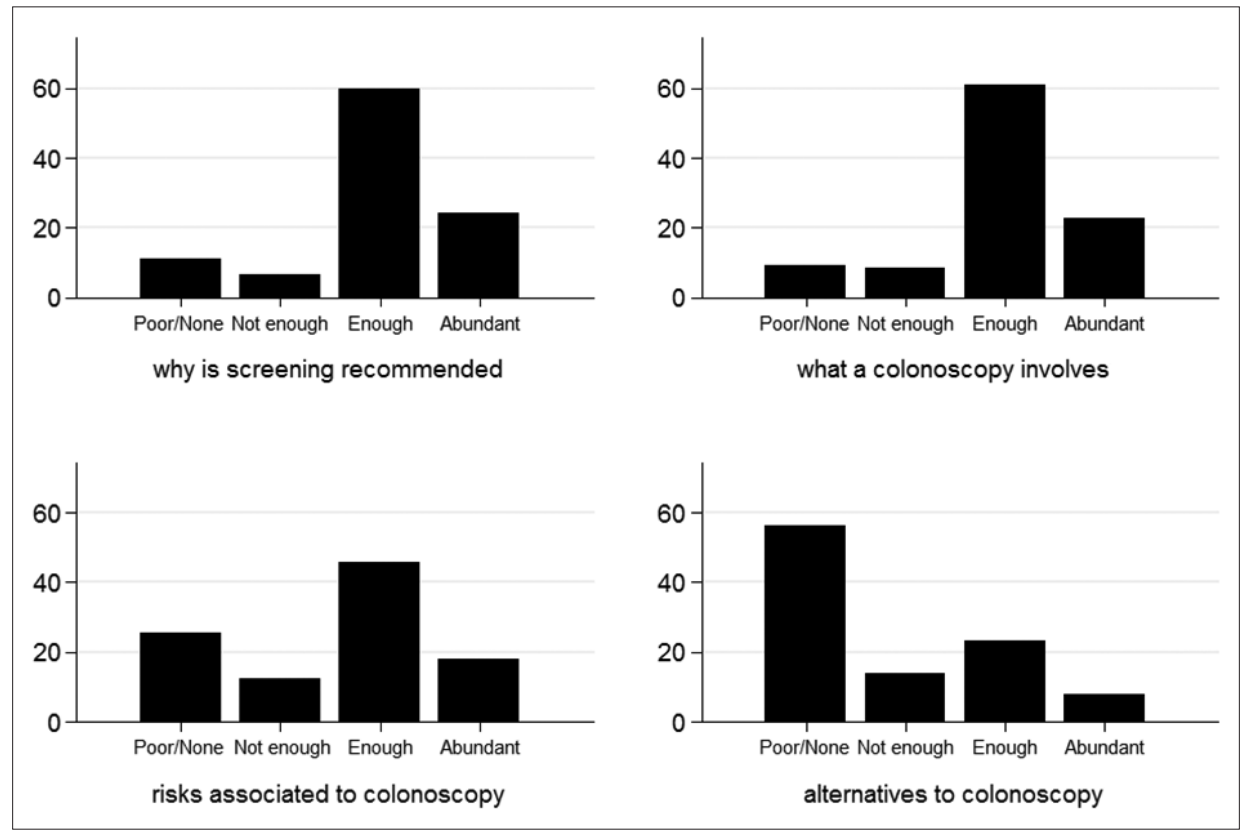

Figure 2 Patients' impression of the information received in the clinical interview in the outpatient gastroenterology clinic (proportion of subjects, \%)

affected family members, sources of information mentioned) and the preference for decision control, as all variables yielded P-values $>0.20$ on univariate multinomial logistic regression.

\section{Knowledge}

Most of our participants (88.5\%; 82.4-92.6\%) were aware of the increased risk of CRC due to family history. The importance 
of bowel cleansing was clear to $95.6 \%$ (91-97.9\%) and $80 \%$ (73-85.5\%) knew that CRC found during screening rounds is usually less extensive. When asked whether taking part in CRC screening decreased the risk of developing CRC cancer, $71.3 \%$ $(63.7-77.8 \%)$ gave a correct answer, while $13.8 \%(9.2-20.1 \%)$ did not know and 15\% (10.2-21.5\%) thought it does not change the risk. On the other hand, 32.1\% (25.1-39.6\%) thought it eliminated the risk of CRC for the next 3 years after screening; 29.5\% (22.8-37.2\%) did not know and only 38.5\% (31.1$46.4 \%)$ knew that a reduced risk still exists. Nearly half of our participants $(46.2 \%$; 38.5-54.1\%) affirmed that CRC screening would lengthen their life expectancy; 25.9\% (19.7-33.4\%) did not know and only $27.8 \%$ (21.4-35.4\%) answered correctly.

A high proportion, $78.8 \%$ (71.5-84.5\%), did not know any alternative to colonoscopy. Only $21.2 \%$ (15.5-26.9\%) could mention at least one, which was occult blood test in all cases. One third of these, $7.1 \%$ (3.9-12.4\%) of the whole sample, were able to report a second method (CT colonography).

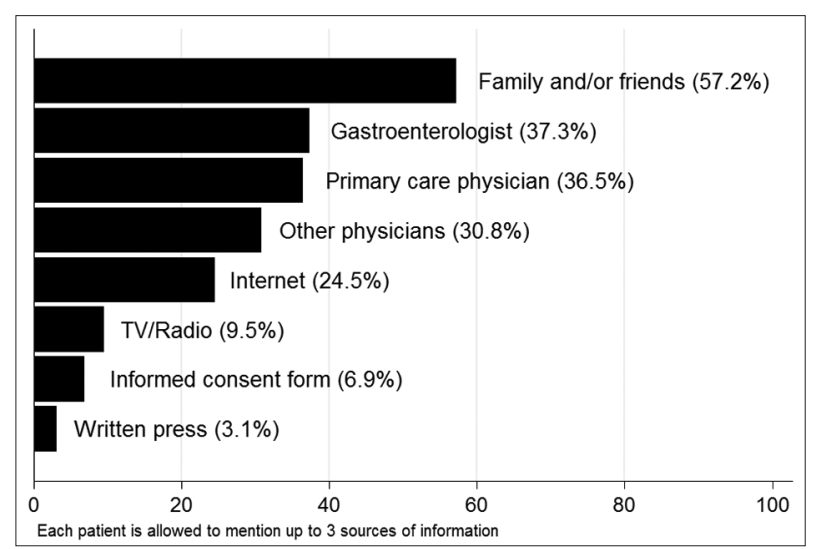

Figure 3 Sources of knowledge about colorectal cancer
At least one possible complication was mentioned by $42.5 \%$ of subjects (35-50.4\%). Hemorrhage was known to $25.6 \%$ (19.4-33\%), colonic perforation to $18.8 \%(13.4-25.6 \%)$ and complications related to sedation to $5.6 \%$ (2.9-10.5\%). In order to enquire about how frequent colonoscopy-related harms were, we considered $0.1-1 \%$ as the correct answer, which was known to $29.7 \%$ (23.1-37.4\%). The majority of participants $(60.1 \%, 52.2-67.5 \%)$ did not know, while 5.6\% (2.9-10-7\%) considered harms to be present in over $1 \%$ of explorations, whereas $4.4 \%(2.1-9.1 \%)$ answered that less than 1 in every 1000 colonoscopies had such complications.

\section{Knowledge score}

The mean knowledge score attained was 4.98 (4.7-5.2). Variables reaching significance on univariate and multivariate analysis are shown in Table 2. Other variables evaluated included sex, previous screening rounds, attitude towards SDM, number of family members affected, sources of information mentioned and delay between the outpatient visit and the interview. Compared with subjects with no education, subjects with a bachelor's degree (or higher education) presented a 70\% better score. A 10-year increase in the attending physician's age was associated with a $10.6 \%$ decrease in the knowledge score.

\section{Relationship between satisfaction and knowledge}

Patients who considered the information they received about why screening is recommended and what a colonoscopy involves to be satisfactory did not show better knowledge of those items. On the other hand, questions about alternatives and risks identified subjects with better knowledge. Those

Table 2 Analysis of factors determining the knowledge score of subjects attending the outpatient gastroenterology clinic between April and August $2014(\mathrm{n}=153)$

\begin{tabular}{|c|c|c|c|c|}
\hline \multirow[t]{2}{*}{ Variable } & \multicolumn{2}{|c|}{ Univariate analysis } & \multicolumn{2}{|c|}{ Multivariate analysis } \\
\hline & IRR (95\% CI) & $P$ value & IRR (95\% CI) & $P$ value \\
\hline Age of the attending physician & $0.99(0.98-0.99)$ & 0.003 & $0.99(0.98-0.99)$ & 0.004 \\
\hline \multicolumn{5}{|l|}{ Educational attainment (None as reference) } \\
\hline Primary & $1.35(0.95-1.92)$ & 0.09 & $1.38(0.97-1.96)$ & 0.08 \\
\hline High school & $1.48(1.04-2.09)$ & 0.03 & $1.53(1.08-2.17)$ & 0.02 \\
\hline Bachelor or higher & $1.81(1.21-2.70)$ & 0.004 & $1.70(1.14-2.54)$ & 0.01 \\
\hline $\begin{array}{l}\text { Time elapsed between diagnosis of the most recent } \\
\text { relative and outpatient visit (years) }\end{array}$ & $0.99(0.99-1.00)$ & 0.09 & & \\
\hline Age & $1(0.99-1.01)$ & 0.17 & & \\
\hline \multicolumn{5}{|l|}{ Sources of information } \\
\hline Gastroenterologist & $1.14(0.99-1.31)$ & 0.07 & & \\
\hline Internet & $1.12(0.96-1.32$ & 0.14 & & \\
\hline TV/Radio & $0.83(0.64-1.07)$ & 0.16 & & \\
\hline
\end{tabular}

IRR, incidence-rate ratio 
satisfied with the information received about alternatives knew more alternatives than those unsatisfied (OR: 5; 2.2-11.3), while those satisfied with information about risks were aware of more harms associated with colonoscopy (OR: 2; 1.1-3.9) and knew their incidence (OR: $3.1 ; 1.4-7.1)$.

\section{Discussion}

Objectively communicating benefits and harms is a difficult task. Overestimation of benefits and underestimation of risks associated with cancer screening is a common problem, as has been shown in previous studies assessing breast cancer screening $[15,16]$, and this may impede future policy changes in public health recommendations [17]. Our interviewees presented better results in questions addressing the benefits of CRC cancer than in those that concerned risks and alternatives. Although this disproportion between information about risks and benefits of CRC screening might be related to screening advocacy campaigns [18], in our study all subjects had discussed CRC screening with both their primary care practitioner and a gastroenterologist. There may be various possible reasons for this deficit. Firstly, overestimation of benefits associated with colonoscopy might be shared by physicians, as shortening colonoscopy intervals is a common problem in CRC screening programs [19]. Secondly, the attending physician's attitude towards SDM may play a role; younger age was significantly associated with better knowledge scores in our sample. This may be related to the increasing interest in SDM in recent years. Thirdly, the fact that current guidelines support colonoscopy as the preferred screening method in subjects with a family history of CRC may prevent some physicians from explaining other alternatives. Last of all, lack of time during the outpatient visit might contribute to this deficit, but patients with previous screening rounds did not show better results, indicating that risks and alternatives are not usually addressed.

Previous studies evaluating patients' preferences show that most patients, between 60 and $90 \%$, favor active or cooperative roles [20-22]. In more recently published studies, when deciding about invasive procedures [23], younger age and a better health status [24] are associated with a preference for active roles. We could not find any factor associated with a preference for active roles. This might be due to the characteristics of our sample (young age, good health status, etc.) or to the trend favoring SDM in recent years. It is important to note that physicians' perceptions of patients' preferences regarding information and decision making are often inaccurate [25]. Previously published papers suggest a relationship between patients' attitudes and values and the choice of CRC screening methods [26-28], but also point out that knowledge of the risks associated with colonoscopy affects this choice [29]. Thus, we consider all patients should be offered the possibility of taking part in the decision-making process.

Our study presents some significant limitations. First, it was a single-center study that included a relatively small number of patients. All gastroenterologists in our unit have worked previously in other centers, but we acknowledge that subjects attended in our institution might not adequately represent the population of our country. Secondly, our knowledge survey has not been previously validated. Thirdly, some factors influencing knowledge were not retrieved, such as the duration of the visit to the gastroenterology outpatient clinic or patients' values. Fourthly, the associations found on multivariate analysis between baseline variables and attitude towards SDM and knowledge scores might underestimate the importance of some of them, as our study was not originally powered to estimate them.

In summary, our study shows that patients with a family history of CRC who undergo CRC screening present insufficient knowledge, centered mainly on colonoscopyassociated risks and alternative screening options. Interviewees are aware of this deficit, as shown by the satisfaction survey. Also important are the strong support for SDM and the interest of new generations of physicians in SDM, as shown from the correlation between physicians' age and knowledge scores. Patients evaluated for CRC screening should be invited to take part in the decision-making process. Alternatives to colonoscopy and risks associated with CRC screening should be more thoroughly addressed. Information given should be presented according to the patient's educational attainment. Interpretation of risks and alternatives by patients might differ, as the impression made by plain numbers is influenced by attitudes and values, but further efforts are needed to assure patients receive accurate, unbiased information.

\section{Summary Box}

\section{What is already known:}

- Colonoscopy is the recommended screening method for subjects with a family history of colorectal cancer (CRC)

- Participants in screening programs are inadequately informed about benefits, risks and alternatives

- Interest in shared decision making (SDM) is increasing

\section{What the new findings are:}

- Information deficits mainly relate to the risks associated with CRC screening and alternatives to colonoscopy

- Patients participating in CRC screening are aware of their information deficits

- Higher educational attainment and younger age of the attending physician are associated with the knowledge acquired

- Patient's attitudes towards SDM cannot be predicted 


\section{References}

1. Ferlay J, Shin HR, Bray F, Forman D, Mathers C, Parkin DM. Estimates of worldwide burden of cancer in 2008: GLOBOCAN 2008. Int J Cancer 2010;127:2893-2917.

2. Steele RJ, McClements $\mathrm{P}$, Watling $\mathrm{C}$, et al. Interval cancers in a FOBT-based colorectal cancer population screening programme: implications for stage, gender and tumour site. Gut 2012;61:576-581.

3. van Rossum LGM, van Rijn AF, Munster IP, et al. Earlier stages of colorectal cancer detected with immunochemical faecal occult blood tests. Neth J Med 2009;67:182-186.

4. Winawer SJ, Zauber AG, Ho MN, et al. Prevention of colorectal cancer by colonoscopic polypectomy. The National Polyp Study Workgroup. N Engl J Med 1993;329:1977-1981.

5. Nishihara R, Wu K, Lochhead P, et al. Long-term colorectal-cancer incidence and mortality after lower endoscopy. $N$ Engl $\mathrm{J} \mathrm{Med}$ 2013;369:1095-1105.

6. Shaukat A, Mongin SJ, Geisser MS, et al. Long-term mortality after screening for colorectal cancer. N Engl J Med 2013;369:1106-1114.

7. Butterworth AS, Higgins JP, Pharoah P. Relative and absolute risk of colorectal cancer for individuals with a family history: a metaanalysis. Eur J Cancer 2006;42:216-227.

8. Rex DK, Johnson DA, Anderson JC, Schoenfeld PS, Burke CA, Inadomi JM; American College of Gastroenterology. American College of Gastroenterology guidelines for colorectal cancer screening 2009 [corrected]. Am J Gastroenterol 2009;104:739-750.

9. Heleno B, Thomsen MF, Rodrigues DS, Jorgensen KJ, Brodersen J. Quantification of harms in cancer screening trials: literature review. BMJ 2013;347:f5334.

10. Bretthauer M, Kalager M. Principles, effectiveness and caveats in screening for cancer. Br J Surg 2013;100:55-65.

11. Stiggelbout AM, Van der Weijden T, De Wit MP, et al. Shared decision making: Really putting patients at the centre of healthcare. BMJ 2012;344:e256.

12. Bassi A, Brown E, Kapoor N, Bodger K. Dissatisfaction with consent for diagnostic gastrointestinal endoscopy. Dig Dis 2002;20:275-279.

13. Degner LF, Sloan JA, Venkatesh P. The Control Preferences Scale. Can J Nurs Res 1997;29:21-43.

14. Shepherd HL, Barratt A, Trevena LJ, et al. Three questions that patients can ask to improve the quality of information physicians give about treatment options: a cross-over trial. Patient Educ Couns 2011;84:379-385.

15. Domenighetti G, D’Avanzo B, Egger M, et al. Women's perception of the benefits of mammography screening: population-based survey in four countries. Int J Epidemiol 2003;32:816-821.

16. Chamot E, Perneger TV. Misconceptions about efficacy of mammography screening: a public health dilemma. J Epidemiol Community Health 2001;55:799-803.

17. Biller-Andorno N, Jüni P. Abolishing mammography screening programs? A view from the Swiss Medical Board. N Engl J Med 2014;370:1965-1967.

18. Woloshin S, Schwartz LM. How a charity oversells mammography. BMJ 2012;345:e5132.

19. Mulder SA, Ouwendijk RJ, van Leerdam ME, Nagengast FM, Kuipers EJ. A nationwide survey evaluating adherence to guidelines for follow-up after polypectomy or treatment for colorectal cancer. J Clin Gastroenterol 2008;42:487-492.

20. Deber RB, Kraetschmer N, Irvine J. What role do patients wish to play in treatment decision making? Arch Intern Med 1996;156:1414-1420.

21. Mazur DJ, Hickam DH. Patients' preferences for risk disclosure and role in decision making for invasive medical procedures. J Gen Intern Med 1997;12:114-117.

22. Messina CR, Lane DS, Grimson R. Colorectal cancer screening attitudes and practices preferences for decision making. Am J Prev Med 2005;28:439-446.

23. Chewning B, Bylund CL, Shah B, Arora NK, Gueguen JA, Makoul G. Patient preferences for shared decisions: A systematic review. Patient Educ Couns 2012;86:9-18.

24. Levinson W, Kao A, Kuby A, Thisted RA. Not all patients want to participate in decision making. A national study of public preferences. J Gen Intern Med 2005;20:531-535.

25. Elkin EB, Kim SH, Casper ES, Kissane DW, Schrag D. Desire for information and involvement in treatment decisions: elderly cancer patients' preferences and their physicians' perceptions. J Clin Oncol 2007;25:5275-5280.

26. Ling BS, Moskowitz MA, Wachs D, Pearson B, Schroy PC. Attitudes toward colorectal cancer screening tests. J Gen Intern Med 2001;16:822-830.

27. Pignone M, Bucholtz D, Harris R. Patient preferences for colon cancer screening. J Gen Intern Med 1999;14:432-437.

28. Leard LE, Savides TJ, Ganiats TG. Patient preferences for colorectal cancer screening. J Fam $\operatorname{Pr}$ 1997;45:211-218.

29. Katsumura $Y$, Yasunaga $H$, Imamura $T$, Ohe $K$, Oyama $H$. Relationship between risk information on total colonoscopy and patient preferences for colorectal cancer screening options: analysis using the analytic hierarchy process. BMC Health Serv Res 2008;8:106. 